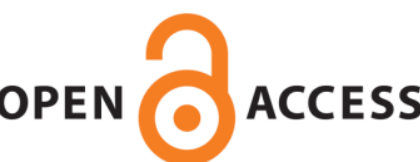

OPEN ACCESS

UWS Academic Portal

\title{
Microplastics in the final ocean frontier
}

Courtene-Jones, Winnie; Quinn, Brian; Gary, Stefan; E. Narayanaswamy, Bhavani

Published: 25/05/2016

Document Version

Publisher's PDF, also known as Version of record

Link to publication on the UWS Academic Portal

Citation for published version (APA):

Courtene-Jones, W., Quinn, B., Gary, S., \& E. Narayanaswamy, B. (2016). Microplastics in the final ocean frontier. Poster session presented at MICRO 2016, Arrecife, Lanzarote, Spain.

\section{General rights}

Copyright and moral rights for the publications made accessible in the UWS Academic Portal are retained by the authors and/or other copyright owners and it is a condition of accessing publications that users recognise and abide by the legal requirements associated with these rights.

\section{Take down policy}

If you believe that this document breaches copyright please contact pure@uws.ac.uk providing details, and we will remove access to the work immediately and investigate your claim. 


\section{Microplastics In The Final Ocean Frontier}

W. Courtene-Jones ${ }^{1}$, B. Quinn ${ }^{2}$, S. Gary ${ }^{1}$, B. Narayanaswamy ${ }^{1}$ winnie.courtene-jones@sams.ac.uk - @WinnieCJ

\section{Introduction}

The deep-sea is classified as the portion of the ocean deeper than 200m off the continental slope (Gage \& Tyler, 1991). This are covers over half of the Earth's surface and supports an incredibly rich diversity of species (Thurber et al. 2014). This remote region has largely remained out of sight out of mind, however the deep-sea is vulnerable to a number of anthropogenic impacts. Macroplastics are recorded extensively in the deep-sea (e.g. Schlining et al. 2013). Concern is mounting regarding microplastics as these small persistent plastics represent one of the greatest threats to ecosystem functioning and services.

Worldwide distribution of microplastics is patchy and current estimates suggest lower quantities in surface waters than expected (Eriksen et al. 2014). Microplastics have been reported in deep-sea sediments (Woodall et al. 2014), hypothesising the deep-sea may be a sink for this pollutant. The ultimate fate of marine microplastics is not well understood; while numerous species are reported to ingest microplastics, currently no studies have considered whether the deep-sea benthic community is also susceptible.

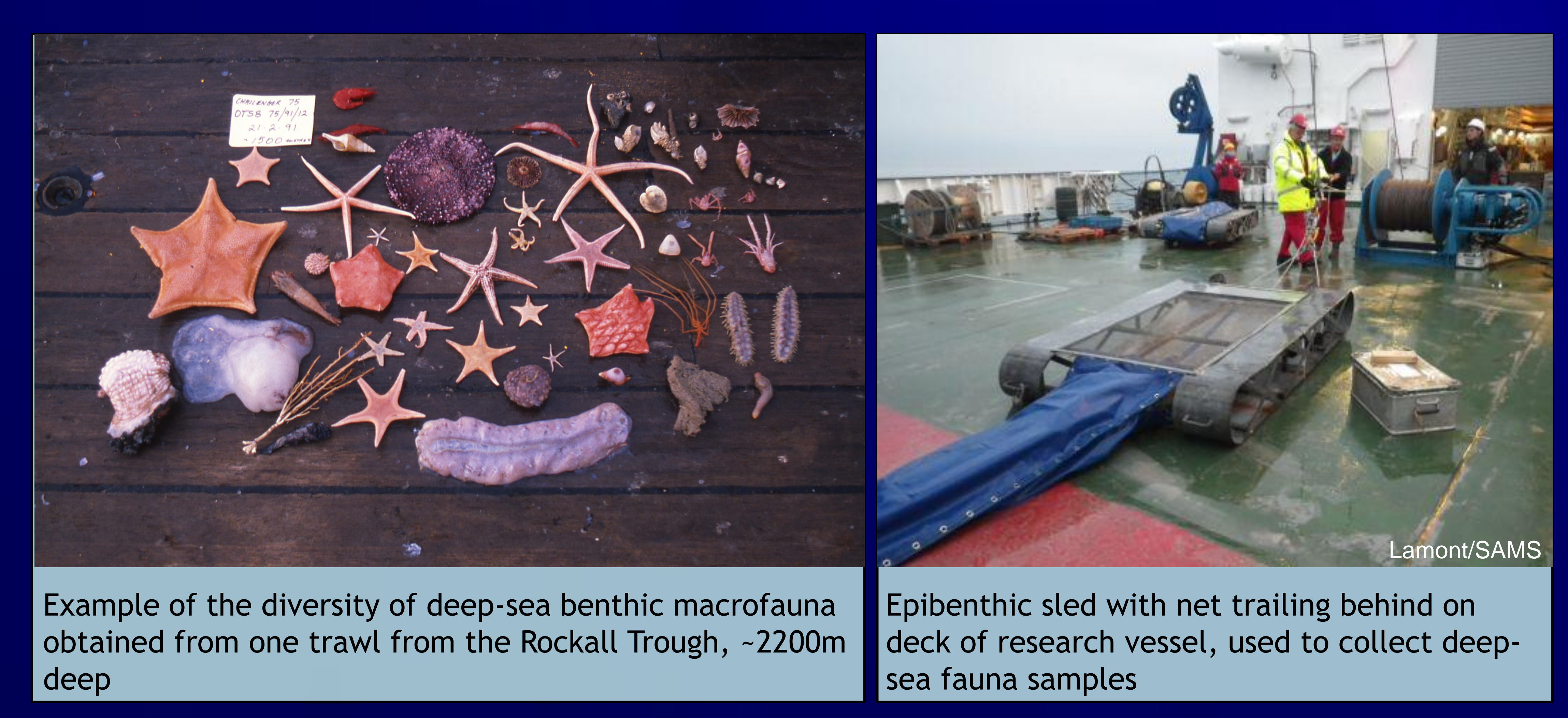

\section{Method}

- Rapid and efficient enzymatic digestion of deep-sea benthic macrofauna

Focus on echinoderms displaying a range of feeding strategies

- Identification \& quantification of ingested microplastics

Visual \& ATR-FTIR spectrometry

Characterise microplastics

Do quantities vary with feeding mechanism?

- Examining historical specimens: Are there decadal trends in ingested microplastics quantities ?

- Modelling distribution \& vertical transport routes of microplastics to Rockall Trough
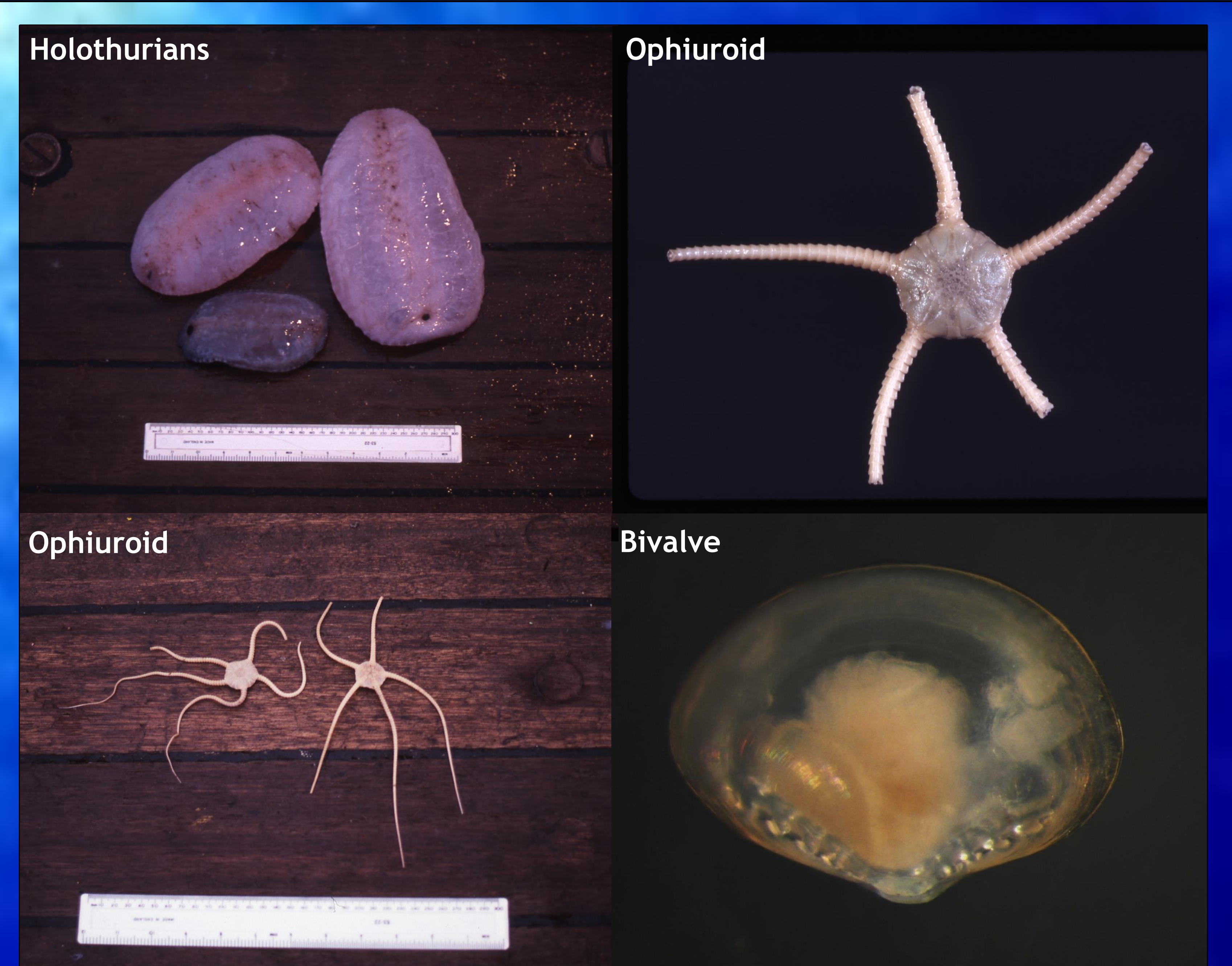

Deep-sea benthic fauna from the Rockall Trough, $\sim 2200 \mathrm{~m}$ deep

\section{Aims}

My study presents first of its kind research, focussing on a long-term time series of deepsea fauna collected from the Rockall Trough dating back to the mid-1970s. I aim to address the following questions:

\section{- Are deep-sea benthic fauna ingesting microplastics? \\ - Can we detect when microplastics arrived in the deep-sea? \\ - What is the timescale and potential vertical transport routes of microplastics to the deep-sea?}

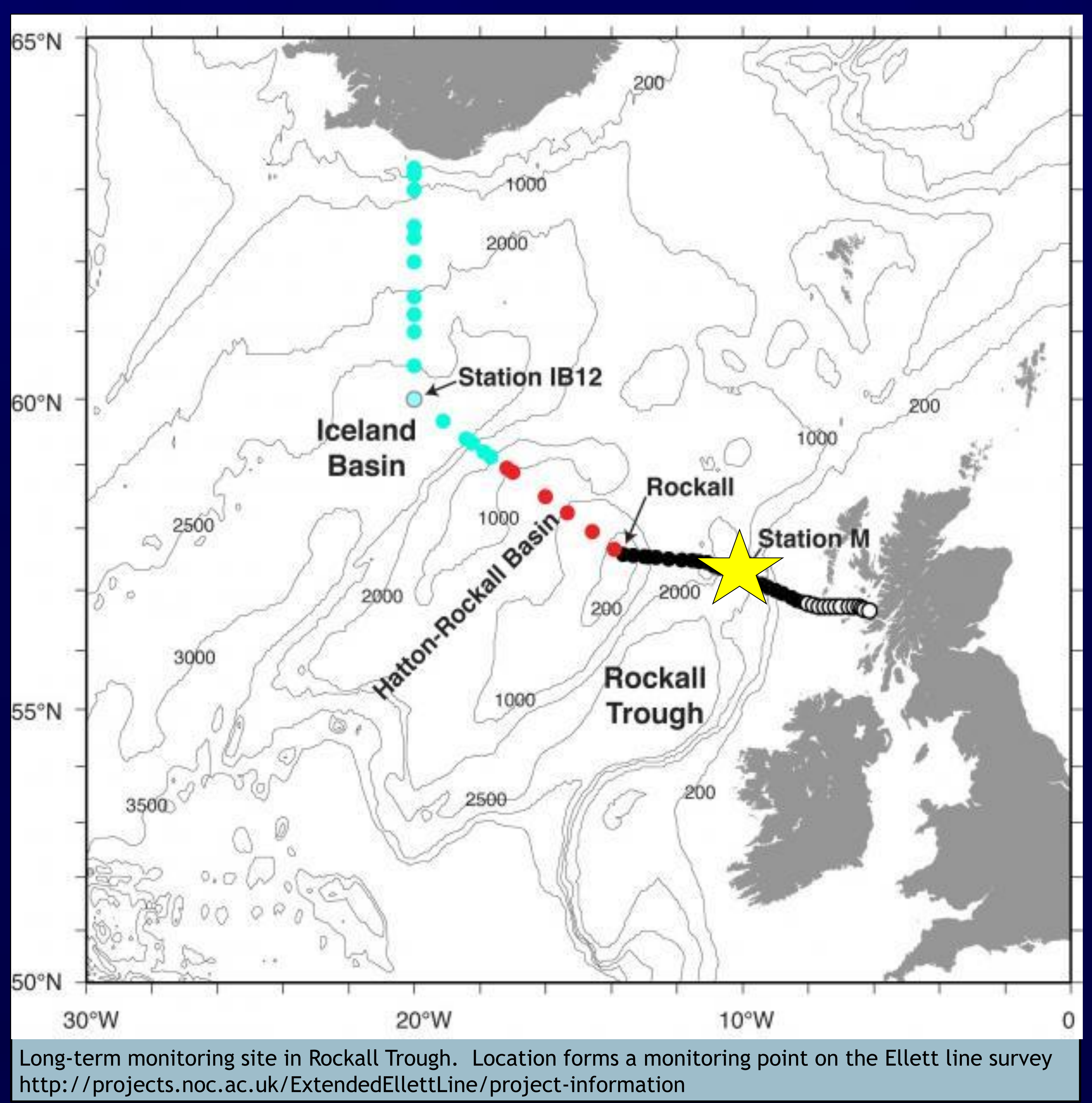

